\title{
Is Supine Position Superior to Prone Position in the Surgical Pinning of Supracondylar Humerus Fracture in Children?
}

\author{
Vito Pavone ${ }^{1, *}$, Andrea Vescio ${ }^{1, *} \mathbb{*}$, Maria Riccioli ${ }^{2}$, Annalisa Culmone ${ }^{1}$, Pierluigi Cosentino ${ }^{1}$, \\ Marco Caponnetto ${ }^{1}$, Sara Dimartino ${ }^{1}$ and Gianluca Testa ${ }^{1}$ (D) \\ 1 Department of General Surgery and Medical Surgical Specialties, Section of Orthopaedics and Traumatology, \\ Surgery, AOU Policlinico-Vittorio Emanuele, University of Catania, 95123 Catania, Italy; \\ annalisa.culmone@libero.it (A.C.); pierluigi-cosentino@hotmail.it (P.C.); caponnettomarco@tiscali.it (M.C.); \\ saradimartino1@gmail.com (S.D.); gianpavel@hotmail.com (G.T.) \\ 2 Dipartimento Area Chirurgica, U.O.C. di Ortopedia e Traumatologia, Ospedale Umberto I di Siracusa, \\ 96100 Siracusa, Italy; marywe@hotmail.it \\ * Correspondence: vitopavone@hotmail.com (V.P.); andreavescio@gmail.com (A.V.)
}

Received: 22 May 2020; Accepted: 29 July 2020; Published: 31 July 2020

\begin{abstract}
Background: Supracondylar humerus fracture (SCHF) is a frequent injury in pediatric ages. Closed reduction and percutaneous pin fixation is a common treatment of displaced SCHF. Surgery is usually performed in the supine position; otherwise the prone position allows an easier fracture reduction and a safe placement of pins. The aim of study is to compare the clinical and radiographic results of the treatment of displaced SCHF, comparing two different intra-operative positionings. Methods: 59 SCHF affected children were retrospectively divided into supine (Group $1 ; n=34$ ) and prone (Group 2; $n=25)$, according to intraoperative position. All treated subjects were clinically evaluated according to Flynn's criteria and Mayo Elbow Performance Score, and radiographically, including the measurement of the Baumann angle. Results: Clinically, Group 1, according Flynn's criteria, had excellent cosmetic outcome in 32 subjects (94.1\%). Mean MAYO Score was $96.0 \pm 3.8$. Group 2, according Flynn's criteria, had excellent cosmetic outcomes in 23 subjects (92.0\%). Mean MAYO Score was $97.8 \pm 3.3$. Radiographically, mean difference of Baumann's angle between the injured limb and the normal limb was $5.5^{\circ} \pm 1.0^{\circ}$ in Group 1 and $5.1^{\circ} \pm 1.1^{\circ}$ in Group 2. Conclusion: Both supine and prone positioning achieved a satisfying outcome with similar results in joint function recovery and complications.
\end{abstract}

Keywords: pediatric fractures; supracondylar humerus fracture; pinning techniques; supine position; prone position

\section{Introduction}

Supracondylar humerus fractures (SCHF) represent $3 \%$ of all pediatric fracture, the most common elbow fracture [1-3] and the second most frequent of upper limb after distal radius fractures [2,3]. Male gender was more frequent, but, after the increase in sports activities the sex ratio is similar. Accounting $90-98 \%$ of injuries, the extension trauma is the most frequent pathogenesis mechanism [4]. The gold standard technique is closed reduction and percutaneous pinning (CRPP) $[5,6]$. Acceptable rotation is achieved if the medial and lateral columns are well aligned [1]. CRPP is a mini-invasive procedure and a safe technique with low rate of complications (2-8\%) [7]. Open reduction is uncommon and limited to selected fractures, such as irreducible fractures by interposition of soft tissues or in cases of neurovascular complications [8,9]. Generally, the supine position is the ordinary placement during surgery [10], but recent findings have shown prone position as an efficient alternative. Despite a 
more challenged airway management [11], prone position achieves a fracture reduction more easily to perform and, at the same time, a safer pins placement can be performed avoiding excess of elbow flexion $[12,13]$.

The purpose of the study is to analyze and compare the clinical and radiological outcomes in SCHF affected patients treated with CRPP in supine or prone position.

\section{Materials and Methods}

\subsection{Sample}

A retrospective medical record review (1st May 2005 to 31st July 2014) was performed, including children younger than 12 years of age who underwent CRPP for displaced SCHFs at our institution. The study was conducted according to the declaration of Helsinki.

The inclusion criteria were as follows: (1) confirmed diagnosis of Gartland type III; (2) patient age under 12 years; (3) trauma in extension resulting from a fall on the palm of the hand with a hyperextended elbow; (4) CPRR treatment within $8 \mathrm{~h}$ according the "treatment protocol" described below; (5) at least 6 months of follow-up; (6) complete clinical and radiographic data.

The exclusion criteria were: (1) poly-traumatized patients with other associated fractures; (2) open or pathological fracture and (3) No complete clinical or radiographic data. According to inclusion and exclusion criteria, 59 subjects were eligible for the study. Informed consent was obtained by all patients.

All patients were admitted through the emergency department with the following demographic and clinical data captured: gender, age at the time of trauma, mechanism of accident, involved side, presence or absence of associated neurovascular injury, and whether the fracture was closed or open." In addition, the intraoperatively patient position was obtained from the medical records (Table 1).

Table 1. Groups demographics characteristics.

\begin{tabular}{cccc}
\hline Characteristics & $\begin{array}{c}\text { Group 1-Supine } \\
\text { Position }(\boldsymbol{n}=\mathbf{3 4})\end{array}$ & $\begin{array}{c}\text { Group 2-Prone } \\
\text { Position }(\boldsymbol{n}=\mathbf{2 5})\end{array}$ & $\boldsymbol{p}$-Value \\
\hline Age (years) & $6.1 \pm 2.8$ & $5.9 \pm 2.3$ & 0.77 \\
Gender (Male/Female) & $22 / 12(64.7 \%)$ & $12 / 13(48 \%)$ & 0.66 \\
Left Side (Left/Right) & $18 / 16$ & $14 / 11$ & 0.53 \\
Follow up (months) & $59.8 \pm 15.8$ & $59.9 \pm 12.8$ & 0.74 \\
\hline
\end{tabular}

Intra-operative positioning choice depended upon surgeon experience and fracture pattern (Figure 1).

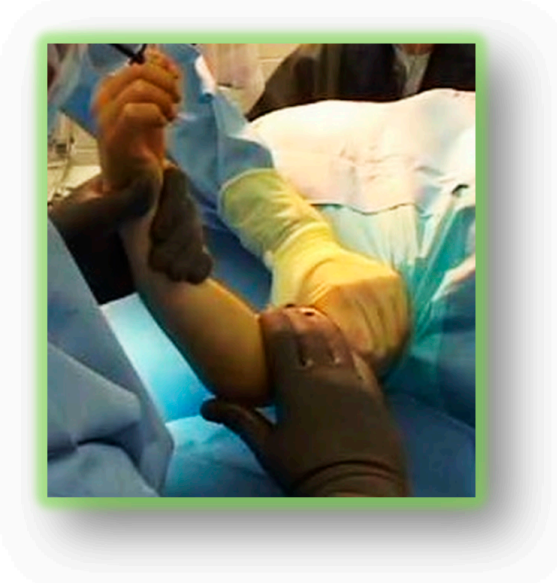

(A)

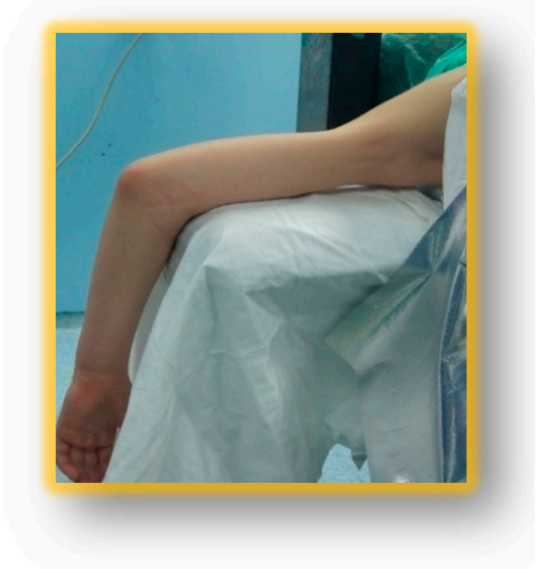

(B)

Figure 1. (A) Supine positioning; (B) Prone positioning. 
Based on the patient position during the surgery, the samples were divided into groups: supine (Group 1; $n=34$ ) and prone (Group 2; $n=25$ ) (Table 1). The cohorts were found similar per demographics characteristics $(p>0.05)$

\subsection{Treatment Protocol}

All subjects were treated within eight hours from presentation with a closed reduction and percutaneous pin fixation. After inducing general anesthesia, the arm was positioned at a " $\mathrm{C}$ " on the brightness amplifier plate. Intra-operative positioning could be supine or prone. According to the age of patients, closed reduction and fixation with 1.6 to $2 \mathrm{~mm} \mathrm{~K}$-wire were used. The adopted configurations were cross-pins or lateral pins [3].

After stabilization with wires, the children were immobilized with a simple posterior splint at 90 degrees of flexion. A clinical and radiographic evaluation was performed at 7 days from surgery. The wires were removed after 4 weeks, to start a rehabilitation protocol to restore the full range of motion of the elbow. All patients were assessed at 1,3,6, and 12 months and then every year.

\subsection{Clinical and Radiological Assessments}

All treated subjects were evaluated clinically according to Flynn's criteria [14] (Table 2) and the Mayo Elbow Performance Score (MEPS) (0-100 points) (Table 3) $[15,16]$ and range of motion (ROM) flexion-extension, as well as, supination and pronation. Both cohorts underwent $\mathrm{X}$-rays at their last follow-up in anteroposterior view and their medicated Baumann's angles [17] were measured.

Table 2. Flynn criteria.

\begin{tabular}{cccc}
\hline Result & Rating & $\begin{array}{c}\text { Cosmetic Factor } \\
\text { Loss of Carrying Angle (degrees) }\end{array}$ & $\begin{array}{c}\text { Functional Factor } \\
\text { Motion Loss (degrees) }\end{array}$ \\
\hline \multirow{3}{*}{ Satisfactory } & Excellent & $0-5$ & $0-5$ \\
& Good & $5-10$ & $5-10$ \\
Unsatisfactory & Fair & $10-15$ & $10-15$ \\
& Poor & $>15$ & $>15$ \\
\hline
\end{tabular}

Table 3. Mayo Elbow Performance Score.

\begin{tabular}{ccc}
\hline Feature & Rating & Score \\
\hline \multirow{3}{*}{ Pain Intensity } & None & 45 \\
& Mild & 30 \\
& Moderate & 15 \\
& Severe & 0 \\
\hline \multirow{3}{*}{ Arc of Motion } & $>100^{\circ}$ & 20 \\
& $50^{\circ}-100^{\circ}$ & 15 \\
& $<50^{\circ}$ & 5 \\
\hline \multirow{3}{*}{ Stability } & Stable & 10 \\
& Moderate instability & 5 \\
& Moderate instability & 0 \\
\hline \multirow{2}{*}{ Function } & Can comb hair & 5 \\
& Can eat & 5 \\
& Can perform hygiene & 5 \\
Maximum Score & Can put on shirt & 5 \\
& Can lace shoe & 5 \\
& & 100 \\
\hline
\end{tabular}

\subsection{Statistical Analysis}

Continuous data are presented as means and standard deviations, as appropriate. The independent sample Student's $t$-test and Fisher's exact test were used to compare age, follow-up, MEPS, range 
of motion for flexion-extension, supination-pronation, and modification of Baumann's Angle means between the groups. The $\chi^{2}$-test was used to verify the homogeneity of the three groups based on gender and laterality-Flynn's criteria. The selected threshold for statistical significance was $p<0.05$. All statistical analyses were performed using the 2016 GraphPad Software (GraphPad Inc., San Diego, CA, USA).

\section{Results}

\subsection{Sample}

Group 1 was composed of 34 patients, 22 (64.7\%) males and 12 (35.3\%) females. The right side was involved in 18 (52.9\%) cases, and the left side in 16 (47.1\%). Mean age at time of surgery was $6.1 \pm$ 2.8 (range 1.0-12.8), mean follow-up was $59.8 \pm 15.8$ months (range 24-79). Group 2 was composed of 25 patients, $12(48 \%)$ male and $13(52 \%)$ female. The right side was involved in $14(56 \%)$ cases, the left side in $11(44 \%)$. Mean age at time of surgery was $5.9 \pm 2.3$ (range 1.5-10.5). Mean follow-up was 59.9 \pm 12.8 months (range 27-78) (Table 1).

\subsection{Clinical and Radiological Assessments}

Group 1, according Flynn's criteria, had an excellent cosmetic outcome in 32 subjects (94.1\%) and good in $2(5.9 \%)$. The functional factor was satisfactory in $33(97 \%)$ patients. Mean MEPS was $96.0 \pm 3.8$ (range 86-100). On examination at final follow-up, the range of motion in the treated arm resulted in values for flexion of $110.9^{\circ} \pm 14.3^{\circ}\left(\right.$ range $\left.90^{\circ}-135^{\circ}\right)$, extension of $3.4^{\circ} \pm 1.8^{\circ}$ (range $0^{\circ}-10^{\circ}$ ), and supination to pronation of $84.9^{\circ} \pm 3.1^{\circ}$ (range $81^{\circ}-90^{\circ}$ ). Group 2, according Flynn's criteria, had excellent cosmetic outcome in 23 subjects $(92.0 \%)$ and good in $2(8.0 \%)$. Functional factor was satisfactory in $100 \%$ of patients. Mean MEPS was $97.8 \pm 3.3$ (range 91-100). At the final follow-up, the range of motion gave a flexion range of about $113.6^{\circ} \pm 11.2^{\circ}\left(\right.$ range $\left.94^{\circ}-137^{\circ}\right)$, extension of $2.9^{\circ} \pm 2.2^{\circ}$ $\left(\right.$ range $\left.0^{\circ}-10^{\circ}\right)$, and supination to pronation of about $86.2^{\circ} \pm 2.2^{\circ}$ (range $84^{\circ}-90^{\circ}$ ).

Radiographically, mean difference of Baumann's angle between the injured limb and the normal limb was $5.5^{\circ} \pm 1.0^{\circ}$ (range $2.7^{\circ}-6.7^{\circ}$ ) in Group 1 and $5.1^{\circ} \pm 1.1^{\circ}$ (range $2.8^{\circ}-6.6^{\circ}$ ) in Group 2. Minor complications encountered. Group 1: asymmetry of $0.8 \mathrm{~cm}$ in one $(2.9 \%)$ case, ulnar nerve paresthesia in 2 cases (5.9\%), which resolved spontaneously in about 2-3 months. Six degrees of varus deviation and $7.5^{\circ}$ deficit of extension were reported in 1 case (2.9\%). Group 2: mild hyperextension in one case $(4 \%)$, local infection treated with antibiotic therapy in two cases $(8 \%)$, spontaneous removal of K-wires in one case $(4 \%)$. No other major complications were reported.

Daily activities and sport participation were restored for all patients. Statistical analysis showed no significant differences between groups (Table 4).

Table 4. Clinical and Radiological assessment results.

\begin{tabular}{|c|c|c|c|c|}
\hline & & Group $1(n=34)$ & Group $2(n=25)$ & $p$-Value \\
\hline \multirow{4}{*}{ Flynn Criteria } & Excellent & $32(94.1 \%)$ & $25(100 \%)$ & \multirow{4}{*}{0.22} \\
\hline & Good & $2(5.9 \%)$ & 0 & \\
\hline & Fair & 0 & 0 & \\
\hline & Poor & 0 & 0 & \\
\hline \multicolumn{2}{|c|}{ Extension } & $3.4 \pm 1.8$ & $2.9 \pm 2.2$ & 0.35 \\
\hline \multicolumn{2}{|c|}{ Flexion } & $110.9 \pm 14.3$ & $113.6 \pm 11.2$ & 0.44 \\
\hline \multicolumn{2}{|c|}{ Supination-Pronation } & $84.9 \pm 3.1$ & $86.2 \pm 2.2$ & 0.08 \\
\hline \multicolumn{2}{|c|}{ Mayo Elbow Performance Score } & $96.0 \pm 3.8$ & $97.8 \pm 3.3$ & 0.06 \\
\hline \multicolumn{2}{|c|}{ Modified Baumann's Angle (deg) } & $5.5 \pm 1.0$ & $5.1 \pm 1.1$ & 0.15 \\
\hline \multicolumn{2}{|c|}{ Reoperations } & 0 & 0 & \\
\hline \multicolumn{2}{|c|}{ Minor Complications } & $4(11.4 \%)$ & $3(12 \%)$ & \\
\hline
\end{tabular}




\section{Discussion}

According our data, supine and prone intraoperative positions are similar for functional and radiological outcomes. At the same time, no differences between both approaches were found, considering complication rate and anesthesia management. SCHFs were widely investigated in literature, but the management and the treatment are still debated; there is no common consensus among the pediatric orthopedics. Despite several societies and expert research committees [18-22] being involved in the development of guidelines and management algorithms, many recommendations are poorly supported by the literature evidence.

Timing of treatment, pin configuration and intraoperative patient position are the most controversial issues. In fact, to postpone surgery could significantly influence the necessity of open reduction approach, complication, or overall outcome [23]. At the same time, several methods have been described. The cross-wired and lateral wires configurations are the most examined [3,24-28]: cross-wired is more biomechanically stable [26,27], lateral reduces nerve injury risk [25].

In 2018, the Italian Pediatric Orthopedic and Traumatology Society (SITOP) guidelines did not highlight the superiority of supine or prone position, considering radiation exposure, surgery length, reduction attempts, clinical and radiological outcome [29,30], and leaving positioning choice to surgeon experience.

Despite the SITOP recommendations, a multicenter study of the main Italian national pediatric trauma centers noted that only 53 out of $529(10 \%)$ patients were surgically treated in prone position [22]. In our series, more than $40 \%$ of the sample was treated in prone position; these patients reported excellent aesthetic and functional outcomes, according to Flynn's Criteria. However, supine positioning patients recorded $94 \%$ of excellent results. De Pellegrin et al. [5] highlighted 100\% of excellent functional outcomes in patients treated in prone position. K. Venkatadass et al. [30] reported the $87.5 \%$ and $89.1 \%$ of satisfaction results for prone and supine position, respectively. Guler et al. [13] compared 27 prone positioned patients to 29 supine and did not found any differences. Hsuan-Kai Kao et al. [31] treated in prone position 10 patients in 7 years, and 90\% of them had excellent outcomes, according to Flynn's criteria.

In our study, as in the series of Gurler et al. [13], both intraoperative positionings reported good and comparable $(p=0.15)$ radiographic outcomes, according to modified Baumann's angle. Hsuan-Kai Kao's study [31] showed that the mean change in Baumann's angle was 3.5.

Considering the equal clinical and radiological results, different authors have listed the advantages of prone intraoperative positioning, such as a simpler reduction, a more comfortable use of C-arm and a reduction in nerve injuries. In case of posterior displacement, the gravity force correctly positions the distal humerus in the frontal plane [32]. Moreover, an easier gravity-guided reduction avoids the elbow hyperflexion, generally needed in patients treated in supine position [33]. During elbow hyperflexion, the ulnar nerve tends to slip anteriorly, out of the cubital tunnel, passing over the medial epicondyle; nerve hypermobility increases iatrogenic injuries through the medial pinning [33]. In our sample, minor complications were encountered, but no nerve injuries; equally, Havlas et al. [11] did not document ulnar nerve iatrogenic lesions in $455 \mathrm{SCHFs}$-affected children treated in prone position. On the other hand, the supine patient position requires minimal time [11], allowing for standard anesthesia management and the possibility to use an anterior, antero-medial or antero-lateral approach, if open reduction is needed [32,34,35].

However, as well as the patient position, other parameters can influence the outcome. The fixation with elastic stable intramedullary nail (ESIN) after close reduction was described [36-38]. ESIN advantages include cast-free treatment after surgery and the protection of the ulnar nerve by introducing the ESIN at the proximal humerus. When compared to K-wire fixation, ESIN are rarely suggested, because they cannot be applied for more complex fractures, due to the necessity of anatomical reduction, to avoid cubitus varus $[39,40]$.

Surgeon experience is another influencing factor for SCHFs-treated patient outcome [41]; Tuomilehto et al. [42] reported a slightly higher rate of complications, but no differences in the 
quality of reduction between residents and senior orthopaedic surgeons; otherwise, the open reduction rate increases when the surgeon is a resident [8].

The limitationss of the study are its retrospective nature, small size, and the lack of objective measurements.

\section{Conclusions}

In conclusion, regarding the surgical pinning of SCHFs, the supine intraoperative positioning is not superior to prone. In both groups, satisfying outcomes were achieved, with similar results in joint function recovery and complications. Surgeon experience is crucial in positioning choice.

Author Contributions: Conceptualization, V.P., G.T. and M.R.; methodology, G.T. and A.V.; software, M.C.; validation, P.C., S.D. and M.R.; formal analysis, A.V.; investigation, V.P.; resources, M.R.; data curation, G.T.; writing-original draft preparation, A.V.; writing-review and editing, G.T., M.R. and A.C.; visualization, G.T.; supervision, V.P.; project administration, V.P. All authors have read and agreed to the published version of the manuscript.

Funding: This research received no external funding.

Acknowledgments: We thank Lorenzo Pavone for editing the manuscript.

Conflicts of Interest: The authors declare no conflict of interest.

\section{References}

1. $\quad$ de Neira, J.Z.S.; Prada-Cañizares, A.; Marti-Ciruelos, R.; Pretell-Mazzini, J. Supracondylar humeral fractures in children: Current concepts for management and prognosis. Int. Orthop. 2015, 39, 2287-2296. [CrossRef]

2. Pavone, V.; Riccioli, M.; Testa, G.; Lucenti, L.; De Cristo, C.; Condorelli, G.; Avondo, S.; Sessa, G. Surgical Treatment of Displaced Supracondylar Pediatric Humerus Fractures: Comparison of Two Pinning Techniques. J. Funct. Morphol. Kinesiol. 2016, 1, 39. [CrossRef]

3. Pavone, V.; Vescio, A.; Lucenti, L.; Chisari, E.; Canavese, F.; Testa, G. Analysis of loss of reduction as risk factor for additional secondary displacement in children with displaced distal radius fractures treated conservatively. Orthop. Traumatol. Surg. Res. 2020, 106, 193-198. [CrossRef]

4. Barron-Torres, E.A.; Sanchez-Cruz, J.F.; Cruz-Melendez, J.R. Clinical and epidemiological characteristic of humeral supracondylar fractures in pediatric patients in a Regional General Hospital. Cir. Cir. 2015, 83, 29-34.

5. De Pellegrin, M.; Brivio, A.; Pescatori, E.; Tessari, L. Supracondylar humerus fractures in children: Closed reduction and cross pin fixation in prone position. GIOT 2008, 34, 199-204.

6. Dua, A.; Eachempati, K.K.; Malhotra, R.; Sharma, L.; Gidaganti, M. Closed reduction and percutaneous pinning of displaced supracondylar fractures of humerus in children with delayed presentation. Chin. J. Traumatol. 2011, 14, 14-19.

7. Gupta, N.; Kay, R.M.; Leitch, K.; Femino, J.D.; Tolo, V.T.; Skaggs, D.L. Effect of surgical delay on perioperative complications and need for open reduction in supracondylar humerus fractures in children. J. Pediatr. Orthop. 2004, 24, 245-248. [CrossRef]

8. Mangwani, J.; Nadarajah, R.; Paterson, J.M. Supracondylar humeral fractures in children: Ten years' experience in a teaching hospital. J. Bone Jt. Surg. Br. 2006, 88, 362-365. [CrossRef]

9. Mommsen, P.; Zeckey, C.; Hildebrand, F.; Frink, M.; Khaladj, N.; Lange, N.; Krettek, C.; Probst, C. Traumatic extremity arterial injury in children: Epidemiology, diagnostics, treatment and prognostic value of Mangl1ed Extremity Severity Score. J. Orthop. Surg. Res. 2010, 15, 25-35. [CrossRef]

10. Skaggs, D.L.; Hale, J.M.; Bassett, J.; Kaminsky, C.; Kay, R.M.; Tolo, V.T. Operative treatment of supracondylar fractures of the humerus in children. The consequences of pin placement. J. Bone Jt. Surg. Am. 2001, 83, 735-740. [CrossRef]

11. Havlas, V.; Trc, T.; Gaheer, R.; Schejbalova, A. Manipulation of pediatric supracondylar fractures of humerus in prone position under general anesthesia. J. Pediatr. Orthop. 2008, 28, 660-664. [CrossRef]

12. Pescatori, E.; Memeo, A.; Brivio, A.; Trapletti, A.; Camurri, S.; Pedretti, L.; Albisetti, W. Supracondylar humerus fractures in children: Comparison of experiences. J. Pediatr. Orthop. B 2012, 21, 505-513. [CrossRef] 
13. Guler, O.; Mutlu, S.; Isyar, M.; Mutlu, H.; Cerci, H.; Mahirogullari, M. Prone versus supine position during surgery for supracondylar humeral fractures. J. Orthop. Surg. (Hong Kong) 2016, 24, 167-169. [CrossRef]

14. Flynn, J.C.; Matthews, J.G.; Benoit, R.L. Blind pinning of displaced supracondylar fractures of the humerus in children. Sixteen years' experience with long-term follow-up. J. Bone Jt. Surg. 1974, 56, 263-272. [CrossRef]

15. Longo, U.G.; Franceschi, F.; Loppini, M.; Maffulli, N.; Denaro, V. Rating systems for evaluation of the elbow. Br. Med. Bull. 2008, 87, 131-161. [CrossRef]

16. Mallo, G.; Stanat, S.J.; Gaffney, J. Use of the Gartland classification system for treatment of pediatric supracondylar humerus fractures. Orthopedics 2010, 33, 19. [CrossRef]

17. Silva, M.; Pandarinath, R.; Farng, E.; Park, S.; Caneda, C.; Fong, Y.J.; Penman, A. Inter- and intra-observer reliability of the Baumann angle of the humerus in children with supracondylar humeral fractures. Int. Orthop. 2010, 34, 553-557. [CrossRef]

18. Heggeness, M.H.; Sanders, J.O.; Murray, J.; Pezold, R.; Sevarino, K.S. Management of Pediatric Supracondylar Humerus Fractures. J. Am. Acad. Orthop. Surg. 2015, 23, e49-e51. [CrossRef]

19. Sanders, J.O.; Heggeness, M.H.; Murray, J.N.; Pezold, R.C.; Sevarino, K.S. Management of Pediatric Supracondylar Humerus Fractures with Vascular Injury. J. Am. Acad. Orthop. Surg. 2016, 24, e21-e23. [CrossRef]

20. Mooney, J.F., III; Hosseinzadeh, P.; Oetgen, M.; Cappello, T. AAOS appropriate use criteria: Management of pediatric supracondylar humerus fractures with vascular injury. J. Am. Acad. Orthop. Surg. 2016, 24, e24-e28. [CrossRef]

21. Mulpuri, K.; Wilkins, K. The treatment of displaced supracondylar humerus fractures: Evidence-based guideline. J. Pediatr. Orthop. 2012, 32, S143-S152. [CrossRef]

22. Marengo, L.; Cravino, M.; Origo, C. Practices concerning management of Gartland type III supracondylar humeral fractures among Italian pediatric orthopedic surgeons. J. Pediatr. Orthop. 2019, 28, 267-270. [CrossRef]

23. Schmid, T.; Joeris, A.; Slongo, T.; Ahmad, S.S.; Ziebarth, K. Displaced supracondylar humeral fractures: Influence of delay of surgery on the incidence of open reduction, complications and outcome. Arch. Orthop. Trauma Surg. 2015, 135, 963-969. [CrossRef]

24. Flierl, M.A.; Carry, P.M.; Scott, F.; Georgopoulos, G.; Hadley-Miller, N. Rotation and displacement predict adverse events in pediatric supracondylar fractures. Orthopedics 2015, 38, e690-e695. [CrossRef]

25. Koehler, S.M.; Sakamoto, S.; Abernathie, B.L.; Hausman, M.R. Arthroscopic correction of a supracondylar malunion in a child. Arthorosc. Tech. 2015, 4, e215-e221. [CrossRef]

26. Brauer, C.A.; Lee, B.M.; Bae, D.S.; Waters, P.M.; Kocher, M.S. A systematic review of medial and lateral entry pinning versus lateral entry pinning for supracondylar fractures of the humerus. J. Pediatr. Orthop. 2007, 27, 181-186. [CrossRef]

27. Larson, L.; Firoozbakhsh, K.; Passarelli, R.; Bosch, P. Biomechanical analysis of pinning techniques for pediatric supracondylar humerus fractures. J. Pediatr. Orthop. 2006, 26, 573-578. [CrossRef]

28. Sibinski, M.; Sharma, H.; Sherlock, D.A. Lateral versus crossed wire fixation for displaced extension supracondylar humeral fractures in children. Injury 2006, 37, 961-965. [CrossRef] [PubMed]

29. Boero, S.; Catena, N.; De Pellegrin, M.; Società Italiana di Ortopedia e Traumatologia Pediatrica (S.I.T.O.P.) Group. Surgical treatment of supracondylar fractures in child. GIOT 2018, 44, 257-263.

30. Venkatadass, K.; Balachandar, G.; Rajasekaran, S. Is Prone Position Ideal for Manipulation and Pinning of Displaced Pediatric Extension-type Supracondylar Fractures of Humerus? A Randomized Control Trial. J. Pediatr. Orthop. 2015, 35, 672-676. [CrossRef] [PubMed]

31. Kao, H.K.; Lee, W.C.; Yang, W.E.; Chang, C.H. Treatment of displaced flexion-type pediatric supracondylar humeral fractures in the prone position. J. Orthop. Surg. (Hong Kong) 2017, 25, 2309499016684412. [CrossRef] [PubMed]

32. De Pellegrin, M.; Fracassetti, D.; Moharamzadeh, D.; Origo, C.; Catena, N. Advantages and disadvantages of the prone position in the surgical treatment of supracondylar humerus fractures in children. A literature review. Injury 2018, 49, S37-S42. [CrossRef] [PubMed]

33. Catena, N.; Calevo, M.G.; Fracassetti, D.; Moharamzadeh, D.; Origo, C.; De Pellegrin, M. Risk of ulnar nerve injury during cross-pinning in supine and prone position for supracondylar humeral fractures in children: A recent literature review. Eur. J. Orthop. Surg. Traumatol. 2019, 29, 1169-1175. [CrossRef] [PubMed] 
34. Anwar, R.; Rahman, N.; Iqbal, M.J.; Khan, M.A. Comparison of the two methods of percutaneous K-wire fixation in displaced supracondylar fracture of the humerus in children. J. Post. Grad. Med. Instr. 2011, 25, 356-361.

35. Barlas, K.; George, B.; Hashmi, F.; Bagga, T. Open medial placement of Kirschner wires for supracondylar humeral fractures in children. J. Orthop. Surg. [Hong Kong] 2006, 14, 53-57. [CrossRef]

36. Lacher, M.; Schaeffer, K.; Boehm, R.; Dietz, H.G. The treatment of supracondylar humeral fractures with elastic stable intramedullary nailing (ESIN) in children. J. Pediatr. Orthop. 2011, 31, 33-38. [CrossRef]

37. Schaffer, K.; Bohm, R.; Dietz, H.G. Elastic stable intramedullary nailing (ESIN) of supracondylar fractures of the humerus in children. Unfallchirurg 2007, 110, 852-858. [CrossRef]

38. Prevot, J.; Lascombes, P.; Metaizeau, J.P.; Blanquart, D. Supracondylar fractures of the humerus in children: Treatment by downward nailing. Rev. Chir. Orthop. Reparatrice Appar. Mot. 1990, 76, 191-197.

39. Wendling-Keim, D.S.; Binder, M.; Dietz, H.G.; Lehner, M. Prognostic Factors for the Outcome of Supracondylar Humeral Fractures in Children. Orthop. Surg. 2019, 11, 690-697. [CrossRef]

40. Kim, W.Y.; Chandru, R.; Bonshahi, A.; Paton, R.W. Displaced supracondylar humeral fractures in children: Results of a national survey of paediatric orthopaedic consultants. Injury 2003, 34, 274-277. [CrossRef]

41. Saarinen, A.J.; Helenius, I. Paediatric supracondylar humeral fractures: The effect of the surgical specialty on the outcomes. J. Child. Orthop. 2019, 13, 40-46. [CrossRef] [PubMed]

42. Tuomilehto, N.; Sommarhem, A.; Nietosvaara, A.Y. 9 years' follow-up of 168 pin-fixed supracondylar humerus fractures in children. Acta Orthop. 2018, 89, 351-356. [CrossRef] [PubMed]

(C) 2020 by the authors. Licensee MDPI, Basel, Switzerland. This article is an open access article distributed under the terms and conditions of the Creative Commons Attribution (CC BY) license (http://creativecommons.org/licenses/by/4.0/). 